\title{
Process Optimization Method for Day Ward Based on Bayesian Decision-Tree
}

\author{
Ting Chen ${ }^{1}$, Kai Pu², Lanzhen Bian ${ }^{3}$, Min $\mathrm{Rao}^{4}$, Jing Hu${ }^{5}$, Rugang Lu ${ }^{1, *}$ and Jinyue Xia ${ }^{6}$ \\ ${ }^{1}$ Department of Day Surgery, Children's Hospital of Nanjing Medical University, Nanjing, 210008, China \\ ${ }^{2}$ Department of Nursing, Children's Hospital of Nanjing Medical University, Nanjing, 210008, China \\ ${ }^{3}$ Department of surgery, Children's Hospital of Nanjing Medical University, Nanjing, 210008, China \\ ${ }^{4}$ Department of rehabilitation, Sichuan Provincial People's Hospital, Chengdu, 610000, China \\ ${ }^{5}$ Department of rehabilitation, Children's Hospital of Nanjing Medical University, Nanjing, 210008, China \\ ${ }^{6}$ International Business Machines Corporation (IBM), NY, 10504, USA \\ *Corresponding Author: Rugang Lu. Email: njetyykfk@163.com \\ Received: 10 August 2021; Accepted: 10 September 2021
}

\begin{abstract}
The day surgery management mode is mainly decentralized management, with clinical departments as the unit, and with reference to the experience of inter project operation management in benchmark hospitals, the empirical management is implemented. With the development of day surgery, the extensive decentralized management mode has been unable to meet the needs of the current day surgery development situation. At first, the paper carefully analyzes the existing problems in the day surgery process in the day ward of the Children's Hospital of Nanjing Medical University. And then, the concerns of doctors, nurses, anesthesiologists and other hospital staff in day ward, children and their parents are considered. Based on Bayesian decision-making theory, this paper optimizes the pre-admission evaluation of sick children and hospitalization process for day surgery in Nanjing Children's Hospital. Moreover, the specific optimization process is designed. After the optimizations, it can be seen that the time consumption of each step of the hospitalization process in day surgery is reduced. Thus, the hospital stay of sick children are significantly reduced, and the operation cost is reduced. In addition, the first preoperative preparation time and the average time of receiving children were reduced in day ward. The satisfaction of children's parents was significantly improved.
\end{abstract}

Keywords: Day ward; process optimization; Bayesian decision tree

\section{Introduction}

The concept of day surgery was first proposed by Scottish paediatrician Nicoll in 1909 [1,2]. In the past 30 years, it has developed rapidly in European and American countries. In 1995, the international association of day surgery was formed by the associations of day surgery in 12 regions and countries, which further promoted the development of day surgery in all countries. In China, day surgery started later. Hong Kong began to carry out day surgery in the 1990s, while hospitals in Wuhan, Shanghai, Chengdu, Beijing and other places did not carry out day surgery until 2001. On October 15, 2015, with the support and

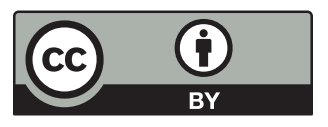

This work is licensed under a Creative Commons Attribution 4.0 International License, which permits unrestricted use, distribution, and reproduction in any medium, provided the original work is properly cited. 
guidance of the Health Development Research Center of the National Health and Family Planning Commission, China Ambulatory Surgery Cooperative Alliance was established. The National

Health and Family Planning Commission has made "promoting day surgery" one of the key tasks of medical and health reform.

The Affiliated Children's Hospital of Nanjing Medical University (Nanjing Children's Hospital and Jiangsu Red Cross Children's Hospital) is a large-scale, Grade III, Grade A comprehensive children's hospital integrating medical treatment, scientific research, teaching, rehabilitation and health care. Since the day surgery was carried out in our hospital in October 2016, the number of day surgery has developed due to the development of the epidemic, reducing the waiting time for appointment, shortening the length of hospital stay and ensuring the safety of surgery have become the biggest demands of patients needing elective surgery. There are many operations in the day ward and the process is fast. After admission, patients were not familiar with the environment and repeatedly asked the nurse about the location and related questions, which led to long preoperative preparation time and affected the process of surgery. After admission, patients' preoperative waiting time was prolonged and patient satisfaction decreased. The patients were not familiar with the perioperative process and discharge process, and could not cooperate well, which led to the decrease of medical work efficiency, the increase of doctor-patient conflicts, and the extension of hospital stay.

Therefore, based on the Bayesian decision tree, this paper carried out research on the above-mentioned problems in the day ward, so as to optimize the treatment process of the day ward, reasonably arrange the operation time, reduce the waiting time of patients, and reduce the medical costs of patients.

The roadmap of this paper is organized as follows. Section 2 introduces the development of ambulatory surgery. Section 3 presents the status and analysis of the problem of day ward. In Section 4, the treatment processing for daytime inpatients is optimized based on Bayesian decision tree. Finally, the conclusion is given in Section 5.

\section{Related Works}

\subsection{Development of Ambulatory Surgery}

With the improvement of medical level and the development of anesthesia technology, as well as the change of medical service and concept of demand, day surgery has made steady development, and great progress has been made in terms of the scale of surgery, surgical methods involved and theoretical and practical research [3,4]. In 2006, the amount of day surgery in the United States, Canada and other countries accounted for $90 \%$ of the total amount of surgery [5]. In 2014, the proportion of day surgery in England and Scotland reached $85 \%$ and $72 \%$ respectively, and the least proportion in other countries also reached 55\% [5-7]. The scale of day surgery is getting larger and larger. However, the development of day surgery in China is still in the primary stage, and the proportion of day surgery in relatively mature hospitals only accounts for about $35 \%$ of the total number of operations, which still has a great space for development. In terms of research on day surgery, foreign countries have abundant research contents. They are good at using scientific research and management tools, and have achieved great achievements in definition, acquisition, nursing, patient satisfaction, therapeutic effect, anesthesia, economic benefits, postoperative recovery and other aspects of day surgery [8-10]. Domestic studies on day surgery mainly focus on the definition, development direction, existing problems [11-13], effect evaluation [14-16], and access of nurses and physicians [17-19], etc., while there are few studies on patient awareness and satisfaction [3-5], as well as the application of professional quality management tools.

In order to ensure the smooth implementation of day surgery, scholars at home and abroad have actively explored every link of the development of day surgery and studied effective measures to promote the 
development of day surgery. From the perspective of management mode, scholars have proposed that the combination of centralized and decentralized management mode [20-22] is the optimal mode for the development of day surgery. Bai et al. [23,24] suggested that the operation process of day surgery [17] should be started to strengthen the process management. Hu et al. [18] emphasized the change of the concept of preoperative fasting and proposed that free intake of clear fluids before anesthesia during day surgery could reduce the incidence of postoperative nausea and vomiting and promote postoperative recovery of patients during daytime. Gong et al. conducted a randomized controlled experiment on daytime and non-daytime patients from the perspective of publicity and education, and the study proved that the full use of preoperative publicity and education could reduce patients' anxiety. It was suggested that medical staff should explain matters for attention during surgery to patients and their families in advance, so as to ensure the smooth implementation of day surgery. And they emphasized the enhancement of postoperative care and follow-up for patients undergoing day surgery, timely treatment of related problems, and promotion of postoperative recovery for patients undergoing day surgery [25-27].

\section{Description of the Current Problem}

The study included 113 sick children with laparoscopic inguinal hernia undergoing day ward surgery from March 2019 to December 2020. Among the 113 sick children: 80 males and 33 females, of which 49 were $0-3$ years old, 49 were 3-6 years old, 15 were $7-10$ years old. The relevant information is shown in Figs. 1 and 2.

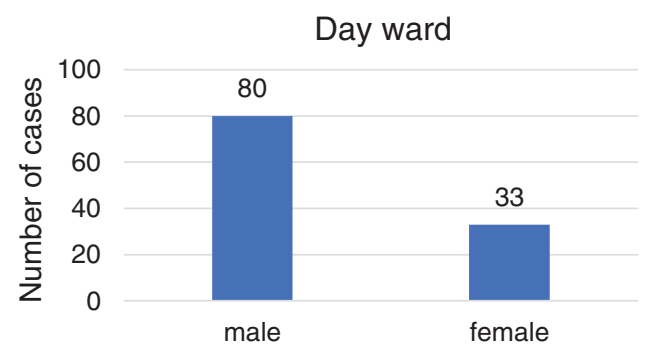

Figure 1: Patient composition of laparoscopic inguinal hernia in day ward

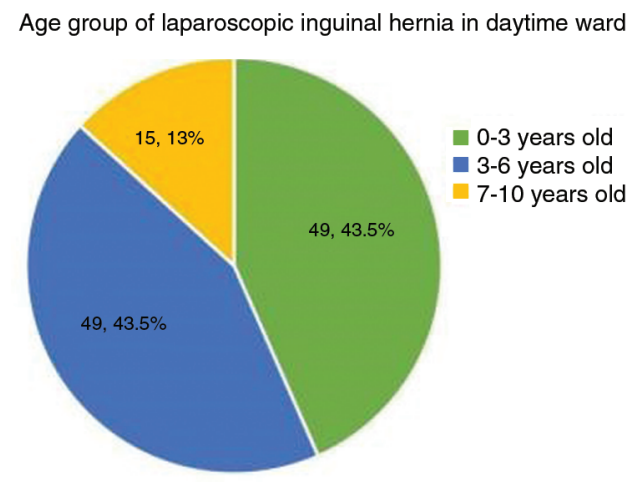

Figure 2: Age group of laparoscopic inguinal hernia in day ward

Research was carried out on doctors, nurses in day ward, doctors, nurses, anesthesiologists in the operating rooms, technicians and nurses in the technical department of the hospital, as well as sick children and their parents. 
The concerns of medical staff are as follows:

a. Increase the utilization rate of beds, improve the turnover rate of beds, increase the types of single diseases of day surgery, appropriately improve the performance income of day surgery ward staff, and improve the initiative to carry out day surgery.

b. Simplify the process of electronic information system for day surgery, use App to monitor the appointment and process of sick children, and timely remind them, so as to avoid the failure to complete the preoperative examination within the prescribed time of day surgery.

c. Set up fast passageway to increase the frequency of daytime examination of equipment to meet the needs of daytime inspections of sick children.

d. Simplify the filling of medical records of day surgery to reduce the workload of doctors and nursing staff.

e. Doctors and anesthesiologists in the operating room who are in charge of the day surgery are informed about the schedule of the operating table at any time, so that the day surgery can be arranged systematically.

f. The operating room arranges operating rooms dedicated for day surgery and relatively fixed operating room anesthesiologists.

g. Caregivers of sick children entering the day surgery ward have civil capacity.

The concerns of sick children and their parents are as follows:

Safety of day surgery, incision length, incision pain, anesthesia recovery time, long waiting time, operation cost, surgical feeding time; poor waiting conditions outside the operating room; poor knowledge of operation related information; difficult to make appointments for various examinations; the precautions for leaving the hospital on the day after the operation; do not know the hospitalization process in advance; do not know the discharge process on the day of discharge; day ward nurses are not familiar with the situation of patients with single disease; the elevator in the operating room is crowded, and the waiting time for the elevator is long; the humanistic care for sick children and psychological counseling their parents are not comprehensive.

\section{Optimization of the Treatment Process for Daytime Inpatients Based on Bayesian Decision Tree 4.1 Bayesian Decision Tree}

Bayesian decision tree is an algorithm that uses a top-down recursive method to perform inductive learning and has high classification accuracy in small-scale samples. Its basic idea is to fill in the missing data attributes according to the maximum posterior assumption in the data preprocessing stage, and to establish a decision tree and add Bayes nodes by comparing the information gain of each attribute. For other classification methods, the advantages of the Bayesian decision tree algorithm include: the data preprocessing stage fills in the missing attributes of some samples to ensure the integrity of the sample population; the construction principle is relatively simple, the builder does not need to know the relevant knowledge of the sample data; the training time is less, and the tree structure is easy to understand; for the samples that lack certain attributes, the Bayesian method can be used to predict their classification more accurately.

\section{Decision tree construction}

\section{(1) Data preprocessing}

Firstly, the sample attributes needed to construct the decision tree are filter out, and the data is divided into two parts: training samples and test samples. Bayesian method is used to fill in the missing training sample data and discretize the data. The naive Bayesian method uses the known sample attributes to 
assign the class $C_{i}$ with the highest posterior probability to the unknown sample attributes. Suppose there are $\mathrm{s}$ data, and the attributes are independent of each other, where $\mathrm{k}$ attributes $x_{1}, x_{2}, \ldots, x_{k}$ are known for data $\mathrm{X}$, but the attribute $\mathrm{x}$ is unknown, the probability that the unknown attribute belongs to the $C_{i}$ class is:

$P\left(C_{i}\right)=\frac{s_{i}}{S}$

$P(X)=P\left(x_{1}\right) P\left(x_{2}\right) \ldots P\left(x_{k}\right)$

$P(C \mid X)=\frac{P\left(X \mid C_{i}\right) P\left(C_{i}\right)}{P(X)}$

$P\left(X \mid C_{i}\right)=P\left(X_{1} \mid C_{i}\right) P\left(X_{2} \mid C_{i}\right) \ldots P\left(X_{k} \mid C_{i}\right)$

\section{(2) Build a decision tree}

Calculate the information gain of each attribute of the root node of the decision tree, select the attribute corresponding to the maximum value as the attribute of the root node, and then recursively calculate the attributes of other child nodes from top to bottom. Suppose the sample has s data, and the leaf nodes have $\mathrm{m}$ different classifications $C_{i}(i=1,2, \ldots, m) ; s_{i}$ is the number of samples in $C_{i}$, and $p_{i}$ is the probability that the sample belongs to $C_{i}$. Suppose that a certain attribute A of a sample has $\mathrm{v}$ different classes. According to the attribute $\mathrm{A}$, the sample $\mathrm{S}$ can be divided into $\mathrm{v}$ subsets, $s_{i j}$ is the number of samples of class $C_{i}$ in the subset $s_{j}$, and $p_{i j}=s_{i j} / s_{j}$ is the probability that the sample in $s_{j}$ belongs to $C_{i}$. Then the expectation I required for sample classification, the entropy $\mathrm{E}(\mathrm{A})$ of the subset according to the attribute A, the expectation I of the subset $s_{j}$, and the information gain $\mathrm{G}(\mathrm{A})$ corresponding to the attribute $\mathrm{A}$ are respectively:

$I\left(s_{1}, s_{2}, \ldots, s_{m}\right)=-\sum_{i=1}^{m} p_{i} l b\left(p_{i}\right)$

$I\left(s_{1 j}+s_{2 j}+\ldots+s_{m j}\right)=-\sum_{i=1}^{m} p_{i j} l b\left(p_{i j}\right)$

$G(A)=I\left(s_{1}+s_{2}+\ldots+s_{m}\right)-E(A)$

$E(A)=\sum_{j=1}^{v} \frac{s_{1 j}+s_{2 j}+\ldots+s_{m j}}{s} I\left(s_{1 j}+s_{2 j}+\ldots+s_{m j}\right)$

\section{(3) Accuracy test of decision tree}

The data of the test sample is traversed through the decision tree from top to bottom, and the final classification result is obtained. When a certain attribute of the test sample is missing, the class with the largest posterior probability is selected as the classification of the sample through the Bayesian algorithm. The final classification is compared with the true classification of the test sample to test the classification accuracy of the decision tree.

\subsection{Surgical Treatment in Day Ward}

Different patients have different conditions, different treatment plans, and different surgical plan pages. Sometimes different treatment plans are used because of different pathological data. In order to overcome this problem, clinical medical experts artificially classify the treatment plans of burn patients, according to the degree of similarity between the patient's burn treatment plan and the patient's burn pathological attributes. The burn treatment plan is divided into 3 categories, which are respectively denoted as F1 (general treatment), F2 (conventional treatment), and F3 (emergency treatment). Through the above preprocessing of the patient's burn pathological attributes and patient treatment plan information table, 
using the test results of 20 hospitalized burn patients as the basic data, a new burn pathological attributetreatment plan information table is obtained, as shown in Tab. 1.

Table 1: Pre-admission assessment form of sick children

\begin{tabular}{|c|c|c|c|c|c|c|c|c|c|c|c|c|c|c|}
\hline No & A & $\mathrm{B}$ & $\mathrm{C}$ & $\mathrm{D}$ & $\mathrm{E}$ & $\mathrm{F}$ & G & $\mathrm{H}$ & I & $\mathrm{J}$ & $\mathrm{K}$ & $\mathrm{L}$ & $\mathrm{M}$ & $\mathrm{N}$ \\
\hline 1 & $\checkmark$ & $\checkmark$ & $\checkmark$ & $\checkmark$ & $\checkmark$ & No & $\checkmark$ & No & No & No & No & No & No & (1) \\
\hline 2 & $\checkmark$ & $\checkmark$ & $\checkmark$ & $\checkmark$ & $\checkmark$ & No & $\checkmark$ & No & $\mathrm{S}$ & No & No & No & No & (1) \\
\hline 3 & $\checkmark$ & $\checkmark$ & $\checkmark$ & $\checkmark$ & $\checkmark$ & No & $\checkmark$ & No & No & $\mathrm{S}$ & No & No & No & (1) \\
\hline 4 & $\checkmark$ & $\checkmark$ & $\checkmark$ & $\checkmark$ & $\checkmark$ & No & $\checkmark$ & No & No & No & Level 1 & No & No & (1) \\
\hline 5 & $\checkmark$ & $\checkmark$ & $\checkmark$ & $\checkmark$ & $\checkmark$ & No & $\checkmark$ & No & No & No & Level 2 & No & No & (2) \\
\hline 6 & $\checkmark$ & $\checkmark$ & $\checkmark$ & $\checkmark$ & $\checkmark$ & No & $\checkmark$ & No & No & No & $\geq$ Level 3 & No & No & (3) \\
\hline 7 & $\checkmark$ & $\checkmark$ & $\checkmark$ & $\checkmark$ & $\checkmark$ & No & $\checkmark$ & No & No & No & No & $\mathrm{S}$ & No & (1) \\
\hline 8 & $\checkmark$ & $\checkmark$ & $\checkmark$ & $\checkmark$ & $\checkmark$ & No & $\checkmark$ & $\mathrm{BMI} \leq 10$ & No & No & No & No & No & (1) \\
\hline 9 & $\checkmark$ & $\checkmark$ & $\checkmark$ & $\checkmark$ & $\checkmark$ & No & $\checkmark$ & $\mathrm{BMI} \leq 20$ & No & No & No & No & No & (2) \\
\hline 10 & $\checkmark$ & $\checkmark$ & $\checkmark$ & $\checkmark$ & $\checkmark$ & No & $\checkmark$ & $\mathrm{BMI} \geq 30$ & No & No & No & No & No & (3) \\
\hline 11 & $x$ & $\checkmark$ & $\checkmark$ & $\checkmark$ & $\checkmark$ & No & $\checkmark$ & No & No & No & No & No & No & (1) \\
\hline 12 & $\checkmark$ & $\checkmark$ & $\checkmark$ & $\checkmark$ & $\beta \pm 10 \%$ & No & $\checkmark$ & No & No & No & No & No & No & (1) \\
\hline 13 & $\checkmark$ & $\checkmark$ & $\checkmark$ & $\checkmark$ & $\beta \pm 10 \%$ & No & $\checkmark$ & No & No & No & No & No & No & (2) \\
\hline 14 & $x$ & $x$ & $\checkmark$ & $\checkmark$ & $\checkmark$ & No & $\checkmark$ & No & No & No & No & No & No & (3) \\
\hline 15 & $x$ & $\checkmark$ & $\checkmark$ & $\checkmark$ & $\checkmark$ & $\mathrm{X}$ & $\checkmark$ & No & No & No & No & No & No & (3) \\
\hline 16 & $\checkmark$ & $\checkmark$ & $\checkmark$ & $\checkmark$ & $\checkmark$ & No & $\checkmark$ & No & $\delta$ & No & No & No & No & \\
\hline 17 & $\checkmark$ & $\checkmark$ & $\checkmark$ & $\checkmark$ & $\checkmark$ & No & $\checkmark$ & No & No & $\delta$ & No & No & No & (3) \\
\hline 18 & $\checkmark$ & $\checkmark$ & $\checkmark$ & $\checkmark$ & $\checkmark$ & No & $\checkmark$ & No & No & No & $\delta$ & No & No & (3) \\
\hline 19 & $\checkmark$ & $\checkmark$ & $\checkmark$ & $\checkmark$ & $\checkmark$ & No & $\checkmark$ & No & No & No & No & No & $\geq \mu$ & (1) \\
\hline 20 & $\checkmark$ & $\checkmark$ & $\checkmark$ & $\checkmark$ & $\checkmark$ & No & $\checkmark$ & No & No & No & No & No & $<\mu$ & (3) \\
\hline 21 & $x$ & $\checkmark$ & $\checkmark$ & $\checkmark$ & $\checkmark$ & No & $x$ & No & No & No & No & No & No & (3) \\
\hline 22 & $\checkmark$ & $\checkmark$ & $\checkmark$ & $\checkmark$ & $\checkmark$ & No & $x$ & No & No & No & No & No & No & (3) \\
\hline 23 & $\checkmark$ & $x$ & $\checkmark$ & $\checkmark$ & $\checkmark$ & No & $\checkmark$ & No & No & No & No & No & No & (3) \\
\hline
\end{tabular}

Notes:

A: Blood routine; B: Prothrombin function; C: Biochemical full set; D: Four items of infectious diseases; E: Blood pressure; F: Acute upper respiratory tract infection; G: Chest radiograph; H: Morbid obesity; I: Diabetes; J: Epilepsy; K: Heart disease (Level of heart function); L: Asthma; M: Premature baby; N: Surgical methods.

$\checkmark$ : Normal; $\boldsymbol{x}$ : Abnormal; S: Stable.

$\beta$ : Normal systolic blood pressure; $\delta$ : Uncontrolled; $\mu$ : 60 weeks.

\subsection{Pre-Admission Assessment}

In order to ensure the safety of day surgery hospitalized sick children, the pre-admission diagnosis and treatment process is optimized. There are no absolute contraindications for day surgery, and each child who needs to enter the day ward for surgery will be evaluated before admission. Before admission, sick children underwent routine examinations of groin, scrotum B-ultrasound, blood routine, coagulation, biochemical full set, blood type, four items of infectious diseases, electrocardiogram, chest CT, respiratory tract anatomical malformation, and patient behavioral and psychological status. 
The following six conditions are included in the daytime surgical assessment items:

A. Acute upper respiratory tract infection or exacerbation of acute upper respiratory tract infection.

B. Obstructive sleep apnea (OSA): 1) Central OSA; 2) OSA without stable control of complications; 3) The patient is unable to comply with the discharge doctor's advice, including the use of continuous positive pressure (CPAP) ventilation device; 4) Resolutely refuse to use CPAP at night after discharge; 5) Patients who need long-acting opioids.

C. Morbid obesity combined with other diseases (body mass index (BMI) $\geq 30$ ).

D. Patients with hypertension, diabetes, epilepsy, heart disease, asthma and other uncontrolled conditions.

E. Patients with recent symptomatic chronic obstructive pulmonary disease.

F. Premature babies within 60 weeks of birth.

Combined with the indications of day surgery and the American Association of Anesthesiologists (ASA) score, as well as the experience of pediatric anesthesiologists, distinguishing sick children suitable for day surgery. Children who need surgery are classified: (1) is all children with normal or stable pointers and can perform day surgery; (2) is mildly abnormal pointer range, and the surgeon judges that day surgery can be performed; (3) is moderate/severe pointer abnormality, and it is recommended to perform elective surgery after treatment. The pre-admission assessment form of children is shown in Tab. 1.

According to the "Guidelines for Pediatric inguinal Hernia Surgery (2017 Edition)" and the clinical experience of the surgeon, (1), (2) can enter the day surgery sequence except for elective surgery after (3) treatment or control of the underlying disease.

\subsection{Optimization of Hospitalization Process for Day Surgery}

According to the above concerns, Bayesian decision trees are generated, and important influencing factors are identified. What is the decision item to calculate the information gain of the above concerns, and the concerns with the maximum information gain is selected as the root node of the decision tree. After calculation, the information of the focus "long waiting time for surgery" has the highest information gain, so it is taken as the root node of the decision tree, and Bayesian nodes are added under the root node. Calculate in turn to build the whole decision tree. Therefore, the following process improvement measures are taken. As shown in Tab. 2.

\subsection{Results}

The hospitalization process capacity of day surgery has been improved.

The operation contents of each link of the day surgery hospitalization process are simplified:

(1) Inpatient appointment for sick children accurate the hospitalization time of the first 8:30 surgical children to half an hour before the operation, reducing the time for patients to wait for surgery in the ward after the hospitalization procedures.

(2) Handling hospitalization procedures at the nurse station: refer to the relevant medical record data of day surgery, establish day surgery cases data template, and speed up the time for nurses to handle hospitalization procedures.

(3) Surgery link: increase the average daily amount of surgery and operating room for day surgery and adjust the allocation of daytime operating room and operating table times.

(4) Postoperative recovery: vigorously develop early rehabilitation in day wards, medical staff receive theoretical knowledge of early rehabilitation and clinical practical operation of skills, which is conducive to postoperative recovery after day surgery. The process optimization program has been in operation for 2 years, after the daytime operation, sick children have no overnight stays and no complications, and they can all be discharged on time. 
Table 2: Improvement of hospitalization procedures for day surgery

\begin{tabular}{|c|c|c|c|c|}
\hline No & $\begin{array}{l}\text { Improvement } \\
\text { contents }\end{array}$ & Improvement measures & Advantages & Shortcomings \\
\hline 1 & $\begin{array}{l}\text { Disinfection } \\
\text { time of the } \\
\text { surgical } \\
\text { abutment }\end{array}$ & $\begin{array}{l}\text { According to the actual } \\
\text { situation of day surgery, } \\
\text { the disinfection time in the } \\
\text { operating room }\end{array}$ & $\begin{array}{l}\text { Reduce the unnecessary } \\
\text { time consumption in the } \\
\text { surgical abutment }\end{array}$ & $\begin{array}{l}\text { Operating room } \\
\text { professionals need to } \\
\text { determine the need for } \\
\text { disinfection in the operating } \\
\text { room based on the actual } \\
\text { situation time }\end{array}$ \\
\hline 2 & $\begin{array}{l}\text { Operating } \\
\text { room } \\
\text { allocation }\end{array}$ & $\begin{array}{l}\text { Allocate operating rooms } \\
\text { reasonably to ensure } \\
\text { smooth use of daytime } \\
\text { operating rooms. Daytime } \\
\text { operations can be arranged } \\
\text { when other operating } \\
\text { rooms are empty }\end{array}$ & $\begin{array}{l}\text { Ensuring sufficient space } \\
\text { for day surgery }\end{array}$ & $\begin{array}{l}\text { The operating room needs a } \\
\text { room for emergency surgery }\end{array}$ \\
\hline 3 & $\begin{array}{l}\text { Hospital stay } \\
\text { appointment }\end{array}$ & $\begin{array}{l}\text { The nurse confirmed the } \\
\text { hospitalization date with } \\
\text { sick children's parents in } \\
\text { advance; the doctor } \\
\text { informed children's } \\
\text { parents of the specific time } \\
\text { to come to the hospital } \\
\text { (accurate to hours) and the } \\
\text { items to be prepared for } \\
\text { admission according to the } \\
\text { operation plan }\end{array}$ & $\begin{array}{l}\text { Shorten patient waiting } \\
\text { time for surgery }\end{array}$ & $\begin{array}{l}\text { It is necessary to consider } \\
\text { various emergencies of sick } \\
\text { children and complete the } \\
\text { clinical experience of } \\
\text { surgeons }\end{array}$ \\
\hline 4 & $\begin{array}{l}\text { Operating } \\
\text { room } \\
\text { schedule } \\
\text { arrangement }\end{array}$ & $\begin{array}{l}\text { The day surgery is } \\
\text { scheduled for the first } \\
\text { operation of the day }\end{array}$ & $\begin{array}{l}\text { Reduce the waiting time of } \\
\text { sick children for operation } \\
\text { and reduce the delay of } \\
\text { daytime operation }\end{array}$ & $\begin{array}{l}\text { Arrangements for } \\
\text { emergency surgery need to } \\
\text { be considered }\end{array}$ \\
\hline 5 & $\begin{array}{l}\text { Day surgery } \\
\text { publicity }\end{array}$ & $\begin{array}{l}\text { Strengthen the publicity of } \\
\text { day surgery ward, make } \\
\text { publicity videos of day } \\
\text { surgery and field publicity } \\
\text { of specialists; the } \\
\text { environment of the day } \\
\text { ward is comfortable, and } \\
\text { light music is played in the } \\
\text { operation waiting room }\end{array}$ & $\begin{array}{l}\text { Increase the correct } \\
\text { understanding of patients } \\
\text { and guardians of day } \\
\text { surgery, understand the } \\
\text { operation process of day } \\
\text { surgery, improve the } \\
\text { cooperation between } \\
\text { doctors and patients }\end{array}$ & $\begin{array}{l}\text { More medical staff with } \\
\text { professional knowledge are } \\
\text { needed }\end{array}$ \\
\hline
\end{tabular}


The time of each link in the day surgery hospitalization process was significantly shortened.

Through the operation of the hospitalization process optimization scheme, the time of each link of the day surgery hospitalization process has been reduced. As shown in Tab. 3, the hospitalization time has been shortened to $8.05 \mathrm{~h}$, the anesthesia recovery time has been shortened by $6.54 \mathrm{~min}$, and the process optimization has achieved some results.

Table 3: Comparison of nursing work efficiency before and after precision management led by nurses

\begin{tabular}{llll}
\hline Group & $\mathrm{n}$ & Preparation time for the first operation & Average time to receive children \\
\hline Control group & 113 & $80.31 \pm 5.84$ & $3.63 \pm 2.22$ \\
Observation group & 113 & $57.96 \pm 8.51$ & $3.01 \pm 0.88$ \\
$\mathrm{t}$ & & 19.963 & 2.415 \\
$\mathrm{p}$ & & 0.000 & 0.017 \\
\hline
\end{tabular}

\section{Work efficiency comparison}

After precision management led by nurses, the preparation time for the first operation and the average time for receiving patients in the observation group were significantly shorter than those in the control group. Compared with before management, the difference was statistically significant $(\mathrm{P}<0.05)$, see Tab. 3 .

\section{Nursing satisfaction comparison}

After the nurse-led precision management, the nursing satisfaction rate of the observation group was $83.40 \%$, compared with $98.60 \%$ of the control group, the difference was statistically significant $(\mathrm{P}<$ 0.05), see Tab. 4.

Table 4: Nursing satisfaction before and after the nurse-led precision management $\mathrm{n}(\%)$

\begin{tabular}{lllllll}
\hline Group & $\mathrm{n}$ & Satisfied & More satisfied & General & Dissatisfied & Very dissatisfied \\
\hline Control group & 113 & $40(35.4)$ & $14(12.4)$ & $47(41.6)$ & $7(6.2)$ & $5(4.4)$ \\
Observation group & 113 & $61(54.0)$ & $21(18.6)$ & $26(23)$ & $3(2.7)$ & $2(1.8)$ \\
\hline
\end{tabular}

\section{Conclusion}

It is necessary to rationalize the operation process of day surgery through process optimization management to promote the development of day surgery. In order to enhance the effect of daytime operation process optimization, it is necessary to systematically design the optimization scheme from the aspects of system, equipment and personnel. The contributions of this paper are as follows. Firstly, this paper optimizes the pre-admission evaluation of sick children and hospitalization process for day surgery in Nanjing Children's Hospital, based on Bayesian decision-making theory. Secondly, through systematic analysis and scientific quantitative data, the effect of optimizing the daytime operation process is significant. The ability of hospitalization process, time-consuming of each step, average length of stay and hospitalization expenses, and doctor-patient satisfaction of day surgery are significantly improved.

Funding Statement: This work is supported by Nanjing Medical Science and Technology Development Project (No. YKK13138). Rugang Lu received the grant and the URLs to sponsors' websites is http:// wjw.nanjing.gov.cn/. 
Conflicts of Interest: The authors declare that they have no conflicts of interest to report regarding the present study.

\section{References}

[1] X. Bai and H. S. Ma, "Research and prospect of comparison between China and abroad in the day surgery development," Chinese Hospital Management, vol. 34, no. 5, pp. 35-37, 2014.

[2] Y. Ren, Y. Leng, J. Qi, K. S. Pradip, J. Wang et al., "Multiple cloud storage mechanism based on blockchain in smart homes," Future Generation Computer Systems, vol. 115, no. 3, pp. 304-313, 2021.

[3] C. Toftgaard and G. Parmentier, "International terminology in ambulatory surgery and its worldwide practice," Day Surgery Development and Practice, vol. 6, no. 5, pp. 35-59, 2006.

[4] J. Hu, L. Zhang, J. Li and Q. Wang, "A new mixed clustering-based method to analyze the gait of children with cerebral palsy," Computers, Materials \& Continua, vol. 66, no. 2, pp. 1551-1562, 2021.

[5] H. S. Ma and Y. Dai, "A brief introduction to the development of day surgery treatment models at home and abroad," Chinese Hospital Management, vol. 32, no. 1, pp. 47-48, 2012.

[6] C. Ge, W. Susilo, Z. Liu, J. Xia, P. Szalachowski et al., "Secure keyword search and data sharing mechanism for cloud computing," IEEE Transactions on Dependable and Secure Computing, vol. 20, no. 8, pp. 1-12, 2020.

[7] Y. J. Ren, F. Zhu, J. Wang, P. Sharma and U. Ghosh, "Novel vote scheme for decision-making feedback based on blockchain in internet of vehicles," IEEE Transactions on Intelligent Transportation Systems, vol. 21, no. 8, pp. $1-10,2021$.

[8] Z. L. Shui and Y. K. Shi, "Discussion on the application of definition and category of day surgery in my country," Chinese Health Service Management, vol. 28, no. 1, pp. 63-65, 2011.

[9] L. Fang, Y. Li, X. Yun, Z. Wen, S. Ji et al., "THP: A novel authentication scheme to prevent multiple attacks in SDN-based IoT network," IEEE Internet of Things Journal, vol. 7, no. 7, pp. 5745-5759, 2020.

[10] G. Xu, X. Li, L. Jiao, W. Wang, A. Liu et al., "BAGKD: A batch authentication and group key distribution protocol for VANETs," IEEE Communications Magazine, vol. 58, no. 7, pp. 35-41, 2020.

[11] N. Du and G. J. Yu, "The effectiveness analysis on implementing day surgery in 13 municipal hospitals in Shanghai," Chinese Hospitals, vol. 14, no. 1, pp. 39-41, 2010.

[12] C. Ge, Z. Liu, J. Xia and L. Fang, "Revocable identity-based broadcast proxy re-encryption for data sharing in clouds," IEEE Transactions on Dependable and Secure Computing, vol. 18, no. 3, pp. 1214-1226, 2021.

[13] Y. Tian, Z. Wang, J. Xiong and J. Ma, "A blockchain-based secure key management scheme with trustworthiness in DWSNs," IEEE Transactions on Industrial Informatics, vol. 16, no. 9, pp. 6193-6202, 2020.

[14] W. D. Liu, P. Li and L. Tan, "Surgical access and challenges of day surgery," West China Medical Journal, vol. 30, no. 5, pp. 820-823, 2015.

[15] J. Xiong, R. Bi, M. Zhao, J. Guo and Q. Yang, "Edge-assisted privacy-preserving raw data sharing framework for connected autonomous vehicles," IEEE Wireless Communications, vol. 27, no. 3, pp. 24-30, 2020.

[16] J. Y. Ren, F. Zhu, K. S. Pradip, T. Wang, J. Wang et al., "Data query mechanism based on hash computing power of blockchain in internet of things," Sensors, vol. 20, no. 1, pp. 1-22, 2020.

[17] X. R. Gong, H. J. Luo and H. Jia, "Practice and study of day surgery in centralized management mode and decentralized management mode," Chinese Hospitals, vol. 19, no. 8, pp. 37-38, 2015.

[18] J. Hu, G. Hu, J. Cai, L. Xu and Q. Wang, "Hospital bed allocation strategy based on queuing theory during the COVID-19 epidemic," Computers, Materials \& Continua, vol. 66, no. 1, pp. 793-803, 2021.

[19] Y. Ren, Y. Leng, Y. Cheng and J. Wang, "Secure data storage based on blockchain and coding in edge computing," Mathematical Biosciences and Engineering, vol. 16, no. 4, pp. 1874-1892, 2019.

[20] C. W. Miao, L. W. Zhong and L. W. Wang, "Practice of different management modes in day surgery," Chinese Hospital Management, vol. 35, no. 3, pp. 21-22, 2015. 
IASC, 2022, vol.32, no.1

[21] X. Lin, H. S. Ma and Q. Wang, "Consideration and suggestions of improving day surgery management in China," Chinese Hospital Management, vol. 37, no. 7, pp. 41-42, 2017.

[22] J. Xu, Q. Meng, J. Wu, J. Zheng, X. Zhang et al., "Efficient and lightweight data streaming authentication in industrial control and automation systems," IEEE Transactions on Industrial Informatics, vol. 17, no. 6, pp. 4279-4287, 2021.

[23] X. Bai, H. S. Ma and Y. Dai, "Research on reengineering of day surgery process and management model optimization," West China Medical Journal, vol. 30, no. 5, pp. 842-845, 2015.

[24] C. P. Ge, W. Susilo, J. Baek, Z. Liu, J. Y. Xia et al., "A verifiable and fair attribute-based proxy re-encryption scheme for data sharing in clouds," IEEE Transactions on Dependable and Secure Computing, vol. 21, no. 7, pp. 1-12, 2021.

[25] C. J. Gong, "Process management experience of cataract day surgery," Chinese Medical Journal of Metallurgical Industry, vol. 34, no. 5, pp. 617-619, 2017.

[26] Y. Ren, J. Qi, Y. Liu, J. Wang and G. Kim, "Integrity verification mechanism of sensor data based on bilinear map accumulator," ACM transactions on Internet Technology, vol. 21, no. 1, pp. 1-19, 2021.

[27] J. Xu, L. Wei, W. Wu, A. Wang and F. Zhou, "Privacy-preserving data integrity verification by using lightweight streaming authenticated data structures for healthcare cyber-physical system," Future Generation Computer Systems, vol. 108, no. 5, pp. 1287-1296, 2020. 